\title{
Resgate do pensamento social latino-americano: crises atuais no Haiti
}

\author{
Rescate del pensamiento social latinoamericano: crisis actuales en Haití \\ Rescuing Latin American Social Thought: Current Crises in Haiti
}

Fednel Saintil ${ }^{1}$

\begin{abstract}
Resumo
A conjuntura do pensamento sócio-político e econômico latino-americano mudam constantemente. Sempre existem grandes discussões sociológicas, politicas e econômicas referentes aos problemas enfrentados pelos países da região. Nos meados do século passado, sobretudo, com a criação da CEPAL o debate se amplia sob outra forma, porém o caso do Haiti, país situado na região caribenha ainda não leva proveito desses debates até para influenciar e pegar um novo rumo. O país entra numa crise politica e economia tremenda sem precedente. De fato, este presente trabalho procura resgatar as discussões de alguns cientistas sociais e economistas latinoamericanos para esclarecer alguns elementos no caso do Haiti durante os últimos tempos. Ao decorrer dos 30 últimos anos, pós-ditadura militar, este período está marcado na historiografia do país como período transitório ao estabelecimento democrático vis a vis à nova ordem mundial. Este trabalho trará alguns fatos que marcaram na essência da sociedade haitiana e procura-se analisa-los referindo as suas principais consequências nos dias atuais.
\end{abstract}

Palavras-chave: América latina; crises; Haiti; Pensamento social; processo de democratização.

\section{Resumen}

La coyuntura del pensamiento sociopolítico y económico latinoamericano cambia constantemente. Siempre hay importantes debates sociológicos, políticos y económicos sobre los problemas que enfrentan los países de la región. A mediados del siglo pasado, especialmente con la creación de la CEPAL, el debate se ha expandido de otra manera, pero el caso de Haití, un país ubicado en la región del Caribe, no aprovecha estos debates ni siquiera para influir y tomar una nueva dirección. El país entra en una crisis política y una economía tremenda sin precedentes. De hecho, este artículo busca rescatar las discusiones de algunos científicos sociales y economistas latinoamericanos para aclarar algunos elementos en el caso de Haití en los últimos tiempos. Durante los últimos 30 años, después de la dictadura militar, este período está marcado en la historiografía del país como un período transitorio para el establecimiento democrático frente al nuevo orden mundial. Este documento traerá algunos hechos que marcaron la esencia de la sociedad haitiana y busca analizarlos en referencia a sus principales consecuencias hoy.

Palabras clave: América Latina; crisis Haití Pensamiento social; proceso de democratización.

\begin{abstract}
The conjuncture of Latin American socio-political and economic thinking changes constantly. There are always major sociological, political and economic discussions regarding the problems faced by countries in the region.

\footnotetext{
${ }^{1}$ Bolsista da CAPES - atualmente mestrando no programa de pós-graduação em economia da Universidade Federal da Bahia- PPGE-UFBA em Salvador (BA). Formado em ciências econômicas - economia, integração e desenvolvimento pela Universidade Federal da Integração Latino-Americana - UNILA (2015 - 2018). Contato: saintilfedy@gmail.com.
} 
In the middle of the last century, especially with the creation of ECLAC, the debate has expanded in another way, but the case of Haiti, a country located in the Caribbean region, does not take advantage of these debates even to influence and take a new direction. The country enters a political crisis and unprecedented tremendous economy. In fact, this paper seeks to rescue the discussions of some Latin American social scientists and economists in order to clarify some elements in the case of Haiti during recent times. During the last 30 years, after the military dictatorship, this period is marked in the country's historiography as a transitory period to the democratic establishment vis a vis the new world order. This paper will bring some facts that marked the essence of Haitian society and seeks to analyze them referring to their main consequences today.

Keyword: Latin America; crises; Haiti, social thinking; democratization process.

\section{Introdução}

Desde a independência do início do século XIX, observa-se que existe uma enorme preocupação e grandes tensões geopolíticas e culturais no contexto latino-americano. Assim, na busca do que faz a especificidade da região, sua identidade, mesmo que seja difícil de conseguir por causa da influência da cultura ocidental. Uma influência que se manifesta através da importação de modelos e, de imitação de linguística, teorias e paradigmas utilizados para explicar e interpretar a realidade social de cada país na região.

Existem diferentes viés de explicação ao se analisar o pensamento econômico e social latino-americano-americano. No decorrer do século XX e XXI. Entre estas vertentes, (Marini, 1997) destacou as seguintes visões: estruturalistas, gramscianas, e vertentes marxistas e cepalinas. Que apresentaram a complexidade do processo no qual a economia, sociedade e cultura, são mantidas em permanente tensão. As mudanças que vieram ocorridas na América latina estão em esferas distintas tais como na política marcada pela presença de governos de vários tipos, tais como: centro-esquerda ou centro-direita, esquerda ou direita, extrema-esquerda ou extrema-direita, liberal, conservador e mudança na economia e mudanças de tipo social também certamente com movimento sindical e grupos sociais e movimentos populares. Neste presente trabalho, resgatamos a vertente marxista a partir das ideias defendidas por alguns teóricos latino-americanos ao longo do século passado para referimo-nos ao caso do Haiti.

\section{Desenvolvimento}

Conforme SILVIO FRONDIZI $(1957)^{2}$, para compreender o estado atual da ordenação das forças sociais em luta, como o das relações entre as várias nações soberanas é

\footnotetext{
${ }^{2}$ Note que há diversas obras que abordaram esta temática, mas escolhemos as que têm o vertente marxista pela questão social. Seria o caso de: FRONDIZI, Sílvio. La Realidad Argentina. Ensayo de interpretación sociológica. Volumen I: El sistema capitalista; volumen II: La revolución socialista. $2^{a}$ Edição. Buenos Aires: Práxis, 1957.
} 
necessário examinar seu processo evolutivo do sistema capitalista. Por conseguinte (BAGÚ, 1978), um dos elementos determinantes que modela as estruturas econômicas e sociais do "novo" continente latino-americano é o capitalismo comercial europeu.

Neste passo, de acordo com o sociólogo (IANNI, 1974), ao focalizar estudando o problema da dependência estrutural, que rege a essência das sociedades latino-americanas, é necessário retomar a perspectiva histórica, de longa duração. Mas, ao referimo-nos ao caso do Haiti, a estrutura era totalmente diferente dos outros países da América Latina quase todo o período colonial.

A estrutura colonial foi rejeitada durante as guerras da independência entre os anos 1791-1803. A partir de 1804 o Haiti se tornava uma nação independente economicamente, politicamente e socialmente. De repente, os demais países da região começarão a ser independentes a partir de 1810 e o processo terminará em 1833. Os processos de colonização das Américas não foram semelhantes integralmente. Cabe dizer que o processo de independência nas colônias espanholas ganhou força no começo do século XIX, aproveitando a fragilidade política em que se encontrava a Espanha, após a invasão das tropas napoleônicas na Europa.

Os novos estados latino-americanos vêm imitando a Europa. Então, percebe-se que existe uma herança colonial vigente na fisionomia cultural, na forma de vestir-se, linguística, ensino educacional, etc. e de fato, pode-se dizer que a cultura latino-americana é eurocêntrica apesar da sua grande diversidade. Em alguns países, existem semelhanças. Na visão critica de alguns teóricos latino-americanos e mesmo europeus, a ideia bolivariana, através da integração entre os Estados recém-nascidos, seria a única a ser aplicada para que os países sejam independentes e soberanos entre si economicamente, politicamente e socialmente.

$\mathrm{Na}$ medida de buscar certamente uma identidade nacional, a liberdade, a soberania cultural, a inclusão social na América latina e no caribe ao longo do tempo especificamente no inicio do século XX, vários teóricos e cientistas sociais latino-americanos discutiram a ideia de incluir os oprimidos e os camponeses e os trabalhadores na realidade social e política, baseando na teoria marxista e, inclusive foram inspirados na pela revolução mexicana na primeira década do século XX e a revolução russa em 1917.

Entre as figuras emblemáticas nas literaturas socioeconômicas, o Victor Haya de la Torre (1895 - 1979) foi um dos principais que abordou essa questão de forma pragmática e justamente com seu programa chamado "APRA". Especificamente, o objetivo deste último era organizar e incentivar as reivindicações dos agricultores: recuperação de terras usurpadas 
sob o porfiriato, expropriação de um terço de grandes propriedades, confisco de hacenderos lutando contra a revolução.

De acordo com Víctor Raúl (1985), a realidade econômico-social do índio americano é o ponto de partida para a ação política, a interpretação da realidade tem sido procurada obstinadamente na Europa.

Por conseguinte, Mariátegui (2008) problematiza a realidade indígena no caso peruano, enviando um recado à conferencia comunista, em 1929, também ele foi uma das figuras marcantes da "APRA". Sua principal preocupação era a exclusão dos índios, ou seja, relatou os problemas dos camponeses indígenas e sua inserção na luta de classes e tentar delimitar a questão crucial da relação dialética entre luta de classes e a luta contra o imperialismo.

Ao decorrer dos anos 1930 a 1950, ocorreu um fenômeno político na América latina, geralmente, referido como populismo principalmente nos países como Brasil, Argentina. Este é uma forma de expressão política que se quer nacional e reformista. Ela é fundamentalmente ligada ao desenvolvimento de novas camadas urbanas: pequena burguesia, empregados e funcionário.

Havia incerteza de saber qual modelo adaptaria a nossa realidade. Por exemplo, pósindependência na América Latina, o nacionalismo tentou reproduzir o anti-liberalismo político e econômico, e adotou uma posição anti-imperialista certamente ligada à esquerda. No entanto, como foi observada por alguns cientistas sociais, a transposição mecânica de sistemas europeus levou alguns partidos comunistas da época (Brasil e Argentina, por exemplo) a serem caracterizados, por vezes, Juan Domingo Perón e Getúlio Vargas do fascismo reprodutivo na América Latina.

\subsection{Ampliação das novas Perspectivas e CEPAL}

No final da década 40 pós-segunda Guerra na América latina, em termos de política econômica, existirá uma sede na qual, diferentes pensadores estarão problematizando a realidade econômica do continente. Inspirando nas politicas macroeconômicas keynesianas, a Cepal sendo criada, será a favor da intervenção do Estado na economia dos países a fim de incentivar o processo de industrialização - o Estado deve planejar o desenvolvimento, particularmente para definir critérios de alocação de recursos entre a produção para exportação.

Assim, 
El punto de partida para entender la contribución de la CEPAL a la historia de las ideas económicas debe ser el reconocimiento de que se trata de un cuerpo analítico específico aplicable a condiciones históricas propias de la periferia latinoamericana. Tal vez sea por eso que cuando se busca el pensamiento cepalino en los principales compendios de historia de la teoría económica son escasas las referencias, circunscritas cuando mucho a la tesis del deterioro de los términos del intercambio y a la tesis estructuralista de la inflación. Esa ausencia lleva a veces a desconocer la fuerza explicativa de ese cuerpo analítico, que deriva de un fértil cruce entre un método esencialmente histórico e inductivo, por un lado, y una referencia abstractoteórica propia -la teoría estructuralista del subdesarrollo periférico latinoamericano-, por el otro (BIELSCHOWSKY, 1998, p. 1).

Conforme (PREBISCH, 1959), o que coloca a América Latina em uma posição periférica dentro do sistema internacional é a divisão internacional do trabalho. Ele veio para correspondê-la como parte da periferia do sistema econômico mundial, o papel específico da produção de alimentos e matérias-primas para os grandes centros industriais. Conforme as palavras do autor é que as economias latino-americanas são insuficientes para satisfazer as suas necessidades mais urgentes de capital.

Nesta logica (FURTADO, 1976) examina as estruturas das economias latinoamericanas impostas pelos conquistadores europeus e suas principais consequências da inserção ao mercado internacional como fontes de matérias primas.

É evidente que a formação coletiva do pensamento socioeconômico latino-americano surgiu recentemente, especificamente nos meados do século XX juntamente com a criação da CEPAL que servirá como um corpo teórico fundamental nas construções de outro viés para o desenvolvimento dos países do continente, rejeitando certamente os princípios da ortodoxia da economia politica no que se refere à inserção ao comercio internacional. Para sintetizar as ideias, na visão deste corpo teórico cepalino, nossos países exportam matérias-primas e importam produtos manufaturados de grande valor agregado. No entanto, a industrialização deveria ser apoiada na "substituição de importações".

Naquele mesmo período de grande debate econômico e politico na região especificamente nas décadas 50 a 70, praticamente quase todos os países conheceram um período de regime militar muito feroz. Agustín Cueva $(1988)^{3}$ faz a crítica aos regimes que se instalaram no cone sul da América Latina, levando em consideração que representaram a implementação de uma ditadura terrorista aberta, munidas dos elementos mais reacionários e apoiadas pelo capital monopolista, exercida contra a classe trabalhadora e a seção revolucionária dos camponeses e intelectuais.

\footnotetext{
${ }^{3}$ CUEVA, Agustín, “Cap. 9-El proceso de industrialización y el problema de la crisis”, em El desarrollo del capitalismo en América Latina, Ed. Siglo XXI, México, 1988, p. 165-183.
} 
O autor deixa claro, pelo conteúdo de classe e forma de exercício de dominação é, inteiramente legítimo e necessário investigar as especificidades do fascismo latino-americano. Registra o fato de que a América Latina é mais ou menos um desses elos fracos por sua condição de região subdesenvolvida e, dependendo dos problemas peculiares do Estado da América Latina no século passado, só pode ser cientificamente compreendido a partir dessa perspectiva leninista. É claro que a crise do mundo capitalista que começou há uma década tem, naturalmente, envolvido todos os países que vivem sob esse sistema, mas não uniformemente.

Por sua vez, André Gunder Frank (1977) lança uma tese sobre "del desarrollo del subdesarrollo", analisando o caso chileno, afirma que o processo capitalista não é um jogo de fases, etapista. Ou seja: os países tidos desenvolvidos hoje, jamais, em uma fase anterior de seu desenvolvimento foram subdesenvolvidos.

Assim, o subdesenvolvimento não é um estágio para se chegar ao desenvolvimento. Para ele, o subdesenvolvimento do Chile é o produto necessário de quatro séculos de desenvolvimento capitalista e as contradições internas do próprio capitalismo, e sua produção. Podendo haver apenas o desenvolvimento do subdesenvolvimento. Como única alternativa estaria a revolução social e a transformação do carácter de classe do Estado latino-americano.

As contradições do desenvolvimento capitalista podem ser vistas como a expropriação-apropriação do excedente econômico, estudado por Marx. O caso do Chile, por exemplo, é caracterizado pela uma economia exportadora capitalista, aberta e dependente, o autor critica vários autores que haviam considerado em síntese que o problema do subdesenvolvimento é o erro de desenvolver-se, para fora em vez de para dentro. Todo o sistema capitalista mundial está gerando contradições também internamente dentro de cada nação e, de fato, essas contradições estão em continuidade com a mudança estrutural e essencial a dar continuidade ao processo de acumulação da estrutura e suas contradições

Marini; Castelo (2015) com "el estado de contrainsurgencia" refere-se ao Estado como a força concentrada da sociedade, a síntese das estruturas e relações de dominação que existem nesta, a existência de um processo contra-revolucionário incide necessariamente sobre ele, afetando-o em sua estrutura e funcionamento.

O autor identifica três vertentes da doutrina de contra-insurgência: a) a própria concepção de política: a contra-insurgência é o aplicativo para a luta política de uma abordagem militar, é semelhante ao da perspectiva de fascismo, vai para o adversário como o inimigo que deve não só ser derrotado, mas aniquilado; b) considera-se o movimento revolucionário como algo estranho à sociedade em que se desenvolve, consulta-se o processo 
revolucionário como subversão causada pela infiltração do inimigo; C) a tentativa de restaurar a saúde do organismo social infectado com a sociedade burguesa sob a sua organização política parlamentar e liberal, explicitamente se propõe a restauração da democracia burguesa. Ao contrário do fascismo, só ele levanta a sua limitação ou suspensão durante a campanha de aniquilação.

Ao discutir o desenvolvimento e subdesenvolvimento na região latino-americana e caribenha, entre alguns autores que enfatizam de forma superficial o caso do Haiti, Furtado (2007), ( BULMER-THOMAS,2010), etc., a obra de (BAMBIRRA 2015), que apresentou uma nova tipologia mais clara dos países latino-americanos a partir de dois grandes tipos de estruturas dependentes: em primeiro os países do tipo A, estes sendo os países cujo processo de industrialização começou antes da primeira guerra mundial, ou seja, nas últimas décadas do século XIX (Brasil, Argentina, México, Uruguai, Chile e em menor medida Colômbia); o segundo é países de tipo $\mathrm{B}$, constituído por aqueles onde tal processo ocorrerá nos anos 50, ou seja, a partir da II Guerra Mundial, vinculado e controlado diretamente pelo capital estrangeiro (Peru, Venezuela, Equador, Costa Rica, Guatemala, Bolívia, El Salvador, Panamá, Nicarágua, Honduras, República Dominicana e Cuba). A professora “autora” Bambirra sugere que seria possível classificar um terceiro tipo $\mathrm{C}$, justamente com os países de estrutura agrário-exportadora, sem diversificação industrial, então poderia incluir o Paraguai, Haiti e, talvez, Panamá.

Então, partindo da lógica de fazer a retrospecção da evolução dos países do continente latino-americano no sistema capitalista, a autora analisa o caráter das contradições do capitalismo dependente na fase da integração monopólica mundial e, no objetivo de alcançar a explicação e a ideologia desenvolvimentista e por sua vez, contribuir para a reformulação das concepções políticas alternativas para ter um processo de industrialização.

\section{Haiti: panorama socioeconômico e politica nas ultimas décadas}

Como observado por Marini (1974), o desenvolvimento histórico do capitalismo não se deu de forma homogênea ou linear na historia do sistema capitalista e mostra que as causas do subdesenvolvimento, estão, na verdade, essencialmente ligadas à estrutura do próprio sistema capitalista. $\mathrm{O}$ autor entende que a história do subdesenvolvimento dos países latinoamericanos é a história do desenvolvimento do sistema capitalista mundial.

De forma geral, os autores citados nos parágrafos anteriores, não tiveram contato ou até não conheceram as transformações internas ocorridas na historiografia haitiana. De fato, 
percebe-se que a realidade haitiana é pouca reconhecida na literatura latino-americana devido a uma questão linguística vinculada ao tipo de colonização conhecido pelo país caribenho.

Em suma, o Haiti, foi o primeiro país cuja população é totalmente negra, fez a primeira revolução em 1791, tornou-se independente depois de mais ou menos 300 anos de escravidão. Existe uma singularidade peculiar durante toda a historiografia do Haiti se comparado com os demais países do continente. Então, o primeiro de janeiro de 1804 os exescravizados ditos escravos negros na ilha de Saint-Domingue marcaram uma nova era na historia da humanidade. Derrubaram aquele sistema de exploração, racismo, desigualdade na colônia francesa.

A revolução social foi bem-sucedida, só que ao longo do tempo haverá problemas e desafios que o povo haitiano não conseguiu superar. Depois de um século e meio, especificamente em 1957 o país conhecerá uma das ditaduras mais drásticas do continente. Em 1986, acabou o regime ditatorial de Duvalier. Logo surgiu uma nova agenda, que o país vai enfrentar um processo de redemocratização que, de certo modo, vem acompanhando de uma nova forma político-econômica vinculada ao consenso de Washington de $1989 .{ }^{4}$

No contexto regional, ao longo das últimas duas décadas, anos 80 e 90 América latina vendo sofrendo uma crise de dívida externa. Conforme as literaturas de historia econômica do Haiti, por exemplo, (MANIGAT, 2009), e outros defensores afirmam que o pagamento da dívida da independência representa uma injustiça social e econômica feita ao povo haitiano que ousou lutar pela liberdade, dignidade e igualdade para todos os homens.

Não cabe aqui apresentar a evolução dos indicadores macroeconômicos agregados neste trabalho, num trabalho futuro sim, pretende-se mostrar empiricamente a tendência de alguns. Todavia, para desenvolver a estrutura produtiva sabe-se que é necessário haver investimento e para ter investimento num país deve ter estabilidade politica e segurança politica para que os investidores tenham um mínimo de confiança apesar de existir outros ricos.

O Haiti vem experimentando momentos terríveis para estabelecer a democracia nas ultimas três décadas. O ambiente político se transforma radicalmente em curtos prazos de tempo, hoje em dia existem mais de 150 partidos políticos no país: o que vem ocorrendo, é que todos querem o poder, essa luta pelo poder chama-se de "fenômeno". Afeta sempre o

\footnotetext{
${ }^{4}$ Ver SAINTIL, Fednel. Um estudo sobre a mudança da pauta das exportações do Haiti: uma abordagem histórico-estrutural. 2018. Trabalho de Conclusão de Curso. - consulte as páginas 38-42.
} 
governo, ao invés de uma coesão interna que priorize o desenvolvimento e/ou crescimento econômico, o governo de turno preocupa-se com os meios de manter-se, ou seja, no combate as inúmeras tentativas de golpe de estado.

Devido à situação política atual do país, a condição de vida no Haiti seja piorada se as diferentes camadas da sociedade, tais como: o governo e a oposição; o governo e a sociedade civil (o povo) não alcançaram um consenso social. Por que os investidores não investem em um país cujo ambiente politico não seja estável, eles observam certos fatores socioeconômicos e políticos antes.

De acordo com o relatório Doing Business 2019, publicado pelo Banco Mundial, o Haiti ocupa a $182^{\mathrm{a}}$ posição entre 190 países. No obstante, essa posição no ranking dos países que têm estrutura para atrair investidores ocupa Haiti, nos faz entender que o país tem problemas sérios, apesar da grande quantidade de mão de obra vacante que existe lá. Deve-se notar também que há o problema dos desastres naturais, por um lado, que impede estruturalmente o desenvolvimento de certos tipos de projetos no território haitiano.

\subsection{Aspectos financeiros e Consequências}

Conforme um artigo publicado por Vaugues (2016) no "Le Nouvelliste", constata que o Estado haitiano conta com recursos da PetroCaribe, doações / ajuda do exterior e financiamento do Banco da República do Haiti (BRH), tudo isso serve para compreender a lacuna fiscal no país. Essas fontes de financiamento, na maioria das vezes, estão secando. Os fluxos da PetroCaribe utilizados pelo Estado somaram US \$ 320 milhões em 2014 e 164 milhões em 2015. Eles serão praticamente reduzidos a um gotejamento em 2016. Quanto às doações externas, diminuíram mais de 75\%, desde 2010, de US \$ 1,8 bilhão para apenas US \$ 488 milhões em 2015. O financiamento monetário do déficit pelo BRH vem aumentando desde 2013, passando de 2,3 bilhões de gourdes para 9,9 bilhões em 2015. Diante desta situação o Banco central do Haiti vem adotando há alguns anos uma política monetária restritiva, usando todos os instrumentos de política monetária disponíveis, notadamente: índices de exigência de reserva, bons BRHs e intervenções no mercado de câmbio. Além disso, a expectativa de mudança parece que está longe. A taxa de cambio em dólar passa em média mais ou menos de 70 gourdes para 95 gourdes de outubro de 2018 a setembro de 2019, respectivamente.

\footnotetext{
${ }^{5}$ Le Nouvelliste é um dos jornais mais lidos no Haiti e mais famoso.
} 
Já a moeda nacional (gourde) vem se desvalorizando de forma acelerada em relação ao dólar, evidentemente, o que provoca o aumento dos preços dos produtos de primeira necessidade (commodities) no mercado haitiano. As famílias haitianas pedem o poder de compra devido à inflação galopante. Conforme as estimativas do $\mathrm{BRH}^{6}$ a taxa de cambio passa de 7,45 gourdes para 93,32 gourdes para ter um dólar americano no período de setembro de 91 a agosto de 2019 , respectivamente.

No entanto, de 2016 para cá, com o envolvimento de alguns lideres do estado no fundo do PetroCaribe e má governança das instituições publicas fazem com que explodiu um escândalo final do ano passado. Quase toda a população vem denunciando o governo e pedindo "onde investiu o fundo PetroCaribe?".

Praticamente estão paralisadas todas as atividades em Porto Príncipe e na maioria das cidades provinciais do Haiti, apesar das mensagens do governo que convidam a população a realizar suas atividades. Nesse contexto de grande fragilidade, dominado por uma tendência crescente de protestos populares exigindo, em particular, a renúncia do Presidente da República, a instalação do julgamento petroCaribe e medidas rápidas e energéticas para recuperar o poder de compra da população. Esses protestos culminaram com impressionantes manifestações populares em massa desde o ano passado em 17 de outubro, 18 de novembro de 2018 e bem no inicio deste ano 7 de fevereiro de 2019, resultando em uma ruptura total entre as 3 potências e o país, com um período impressionante de 10 dias de cessação quase total de qualquer atividade econômica no país conforme PAPDA , FONDAMA (2019) ${ }^{7}$

\section{Considerações finais}

Para compreender o mundo em que vivemos, para entender nosso presente, para conhecermo-nos melhor sendo elementos de um conjunto muito complexo que é um Estado dentro o sistema capitalista, é preciso fazer uma retrospectiva da historia. É necessário ler e compreender a historia para nos saber de verdade quem somos. Como os autores citados fizeram, olharam para a trajetória da evolução dos estudos histórico, econômico e mesmo politico para problematiza a realidade dos países. Entende-se que realmente a ciência social é

\footnotetext{
${ }^{6}$ BRH: Banque de la République d’Haiti. < https://www.brh.ht/brh/politique-monetaire/taux-de-change/>
}

${ }^{7}$ PAPADA. CADTM Haïti - «Plateforme Haïtienne de Plaidoyer pour un Développement Alternatif »= Plataforma de advocacia haitiana para desenvolvimento alternativo. Tradução própria. 
extremamente importante na combinação das áreas de conhecimento citado de certo modo para encontrar alternativas que não sejam padronizadas conforme as que os países hegemônicos nos propuseram. Como vimos ao longo do século XX, na região latinoamericana havia debates importantíssimos nas diferentes esferas sociais e até os momentos atuais as mesmas conversas e debates estão em nossas realidades.

Assim, devido à incerteza política, falta de credibilidade, fraca governança e liderança e etc., fatores e elementos relevantes, ou seja, uma série de variáveis que podem ter repercussões tremendas na crise do Haiti no sistema capitalista. Conclui-se dizendo que o debate sobre a construção de um Estado Nacional, forte e desenvolvido nunca foi ampliado no Haiti, ou seja, os problemas atuais do país estão entrelaçados nos mesmos erros que todos os governos anteriores cometeram, em outras palavras, o governo atual não consegue alcançar este nível abstração. Já o sistema político estabelecido é de um alto grau de corrupção, além disso, observa-se que trata de um sistema que não é adequado ao Haiti. Em breve, se não tiver um consenso num dialogo nacional entre o setor publico e a sociedade civil, os empresários etc., poderá o futuro ser ainda pior para o Haiti, até conhecer uma nova ocupação militar dos países dominantes do sistema capitalista.

Por fim, o Haiti precisa aprender através seus erros. Por isso, é bom saber a historia. Então, compreende-se que a saída da crise do Haiti não depende dos ONGs que estão no país, nem dos países ditos "Pays amis" de Haiti. Conhecer os fundamentos da América Latina, refletir sobre os problemas a partir da colonização e problematizando nossas realidades de hoje ao referimo-nos a um pensamento social e critico, seria uma talvez uma alternativa para termos uma nova América, um novo Haiti, que não seja dependente de forma econômica e politicamente.

\section{Referencias}

BAGÚ, Sergio. El tiempo de la realidad social. México, México: Siglo XXI, 1978.

BAMBIRRA, V. O Capitalismo Dependente Latino-Americano. 3. ed. Florianópolis: Insular, 2015.

BIELSCHOWSKY, Ricardo. Evolución de las ideas de la CEPAL. Revista de la CEPAL, 1998.

BRH: Banque de la République d’Haiti. Politique monétaire - Taux de change. < https://www.brh.ht/brh/politique-monetaire/taux-de-change/>. 
BULMER-THOMAS, V. La historia económica de América Latina desde la independencia. 2. ed. México: Fondo de Cultura Económica, 2010.

CUEVA, Agustín, El desarrollo del capitalismo en América Latina. Ed. Siglo XXI, México, 1988, p. 165-183.

FRANK, Andrés G. El desarrollo y el subdesarrollo. 1977.

FRONDIZI, Sílvio. La Realidad Argentina. Ensayo de interpretación sociológica. Volumen I: El sistema capitalista; volumen II: La revolución socialista. $2^{\mathrm{a}}$ Edição. Buenos Aires: Práxis, 1957.

FURTADO, C. A economia latino-americana: formação histórica e problemas contemporâneos. São Paulo: Companhia das letras, 2007.

GUILLEN, Romo Hector. De la pensée de la CEPAL au néo-libéralisme, du néolibéralisme au néo-structuralisme, une revue de la littérature sud-américaine. In: TiersMonde, tome 35, $\mathrm{n}^{\circ} 140,1994$. pp. 907-926.

HAYA DE LA TORRE, Victor Raúl. Obras Completas, Lima. Editorial Juan Mejía Baca, 1985.

IANNI, O. - O imperialismo na America Latina, Ed. Civilização Brasileira, 1974.

JAMES, C. L. R. Os jacobinos negros: Toussaint L'Ouverture e a revolução de São Domingos. Perdizes: Boitempo, 2000.

MANIGAT, L. F. La crise haitienne contemporaine: retrospective et perspective dans la saisie du point critique d'aujourd'hui: une lecture d'historien-politologue. Collection du CHUDAC. Port-au-prince: Media-texte, 2009.

MARIÁTEGUI, José Carlos. Sete ensaios de interpretação da realidade peruana. São Paulo, Editora Expressão Popular, 2008.

MARINI, Ruy Mauro. Subdsarollo y revolución. México: Siglo Veintiuno Editores, 1970.

MARINI, Ruy Mauro; CASTELO, Rodrigo. O Estado de Contra-Insurgência. Revista de Estudos e Pesquisas sobre as Américas, v. 12, n. 3, p. 1-15, 2015.

MARINI, Ruy Mauro; SADER, Emir. Dialéctica de la dependencia. México: Era, 1974.

PAPDA, FONDAMA. Les luttes paysannes et la crise haïtienne, CADTM, 26 abril 2019. Disponivel em : 〈http://www.cadtm.org/Les-luttes-paysannes-et-la-crise-haitienne>.

PREBISCH, Raul. Commercial policy in the underdeveloped countries. The American Economic Review, v. 49, n. 2, p. 251-273, 1959.

SAINTIL, Fednel. Um estudo sobre a mudança da pauta das exportações do Haiti: uma abordagem histórico-estrutural. 2018. Trabalho de Conclusão de Curso. 
VAUGUES, Gérard. Haïti 2016: La situation économique en pleine crise politique. Le nouvelliste, Publié le 26/04/2016. Acesso em 28/09/19. Disponível em: < https://lenouvelliste.com/lenouvelliste/article/158243/Haiti-2016-La-situation-economiqueen-pleine-crise-politique>.

WORLD BANK GROUP. Doing business 2019: Training for reform. 16th Edition.

Disponivél em: <http://www.worldbank.org/content/dam/doingBusiness/media/Annual-

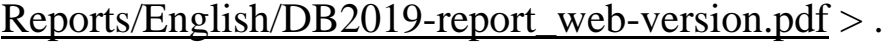

